Original Research Paper

\title{
A Proposed Design for Illumination and Cameras Surveillance System for Optimum Supervision at a Perimeter Area of Nuclear Facility
}

\author{
Amir Abdel Wadoud and Alaa Abdelwahab Saleh \\ Department of Nuclear Reactors, \\ Nuclear Research Center, Inshas, P.O. Box 13759, Atomic Energy Authority, Cairo, Egypt
}

\author{
Article history \\ Received: 07-10-2016 \\ Revised: 01-01-2017 \\ Accepted: $30-01-2018$ \\ Corresponding Author: \\ Alaa Abdelwahab Saleh \\ Department of Nuclear \\ Reactors, Nuclear Research \\ Center, Inshas, P.O. Box \\ 13759, Atomic Energy \\ Authority, Cairo, Egypt \\ Email: alaa91071@yahoo.com
}

\begin{abstract}
An important component of a comprehensive security plan is lighting. Security Protective Lighting has three functional objectives: To illuminate a person, object, place or condition of security to permit observation and identification, to be a physical deterrent through the glare effect of direct light on the human eye and to be a psychological deterrent creating in an intruder's mind the awareness that he or she will be discovered and observed during any unauthorized entry attempt. The most obvious reason for protective lighting is to make certain any person, object, place or condition will be sufficiently illuminated to provide effective security in a given region. Where perimeter lighting is required, the lighting units for a perimeter fence should be located a sufficient distance within the protected area and above the fence so that the light pattern on the ground will include an area both inside and outside the fence. Perimeter lighting should be continuous and on both sides of the perimeter fence and should be sufficient to support CCTV and other surveillance equipment where required. The cone of illumination from lighting units should be directed downward and outward from the structure or area being protected. The lighting should be arranged so as to create minimal shadows and minimal glare in the eyes of security guards. In this study a proposed design for security lighting and cameras surveillance system for optimum supervision at a perimeter area of a hypothetical nuclear facility will be presented. The illumination poles, lamps type, towers space distance, average and minimum Lighting Levels and Tilt Angle, required for camera surveillance system will be computed and determined. The work provides the requirements of cameras surveillance system at nuclear reactors isolation zone. Width of images sensitive area, lens focal length, lens format and angel of view will be determined by calculation method. The work determines cameras type, distributions, camera's parameters and formulas according to the physical protection design process. Cameras angles of view, Lens Format, Lens focal length, F-Number and angle of view will be calculated. The optimum designing results for the security lighting ( 35 poles with 250 watt high pressure sodium and $34 \mathrm{~m}$ poles span with minimum lighting level equal 7 lux. The optimum CCTV design resulting in 15 cameras with length format 0.25 inch, length focal length $50 \mathrm{~mm}$, F-stop number 1.8 , angle of view 5.26 degree. In the future work; designers should consider the natural properties of reflectance, light absorption capacity, mobility and an object's inherent sensitivity to light to be sufficient to support CCTV system.
\end{abstract}

Keywords: Security Lighting, Illumination, Perimeter Area, Cameras Surveillance System 


\section{Introduction}

Security lighting is an important part of the perimeter security plan. On most projects, however, little consideration is given to the security lighting design. Usually, lights are installed with respect to global lighting design and with on consideration to security. Then the security department suffers from the bad images from the Closed Circuit Television system (CCTV) along the perimeter area. The main objects for security lighting are to make an intruder visible, unable to use the cover of darkness to access the perimeter security. Security lighting also will enhance the effectiveness of any security force on site by providing a clear view of the property through the CCTV. To determine the security lighting requirements for the location, we need to know what we are trying to protect and from whom must be protected. Table (1) shows the lighting requirements for various areas. The table outlines the minimum Lux (foot-candles) needed for each area (Michael and Arata, 2006). The lighting also will aid the CCTV system by providing the necessary light for capturing useful images for security and investigations of unauthorized entries to the site as well as identifying any vandals. Security lighting is inexpensive to maintain and will aid security forces by reducing the advantages of concealment and surprise for the motivated intruder. Security lighting alone will not discourage an unauthorized person from attempting to enter the site, but the lighting will assist security personnel in detecting the unauthorized person. The lighting will enable the security force to observe activities around the site while minimizing the presence of the security force. To accomplish this task, security lighting must create contrast between the intruder and the background. For painted surfaces, grass, clean concrete and brick walls, the lighting does not need to be as intense. The lighting must be more intense to contrast an intruder from a dark or dirty background. Eliminating shadowing is another important consideration in the design of the security. The CCTV is essential to identify the cause of an alarm (intrusion process) and to determine if the alarm is true or false. With a CCTV system, security personnel can rapidly assess sensors alarms at remote locations. The CCTV system has two purposes; the first is to determine the cause of a sensor alarm and determining whether the alarm is true or false. The second purpose is to provide information about an intrusion. The CCTV system is composing of several cameras at the vital areas, a display monitor at the local end, various transmission, switching and recording devices. Whereas CCTV previously required especially high illumination levels, current CCTV cameras can function under very low light levels.
Table 1: Foot-candles permitted for security lighting (Michael and Arata, 2006)

\begin{tabular}{ll}
\hline Location & $\begin{array}{l}\text { Lux (foot-candles) Required } \\
\text { at level on ground }\end{array}$ \\
\hline Perimeter fence & $5(0.5)$ \\
Buildings & $5-20(0.5-2)$ \\
Large open areas & $5-20(0.5-2)$ \\
Entrances & $100(10)$ \\
Gatehouses & $300(30)$ \\
Walkways and access points & $40-60(4-6)$ \\
\hline
\end{tabular}

Kukula and Elliot found that the "failure to enroll" rate for an automatic face-identification system was only $6.3 \%$ under 10 lux, compared with 3.2\% under 410 lux (Kukula and Elliott, 2004). Vermeulem found that a CCTV camera with a "good quality lens" required 26 lux for "excellent picture quality" (Vermeulen, 1992). This value can be expected to have dropped very dramatically since 1992. Indeed, some modern infra-red CCTV cameras specifically require very low light levels for proper functioning. The following information needs to be provided to designers which will enable them to evaluate the site plan for proper perimeter lighting:

1. Where perimeter lighting is required, the lighting units for a perimeter fence should be located a sufficient distance within the protected area and above the fence so that the light pattern on the ground will include an area both inside and outside the fence

2. Perimeter lighting should be continuous and on both sides of the perimeter fence and should be sufficient to support CCTV and other surveillance equipment where required

3. The cone of illumination from lighting units should be directed downward and outward from the structure or area being protected. Cones of illumination should overlap to provide coverage in the event of bulb burnout

4. The lighting should be arranged so as to create minimal shadows and minimal glare in the eyes of security guards

5. The lighting plan should include a key to the proposed lighting that provides the following information:

a. Type and number of luminaries fixtures, including the "cut off characteristics"

b. Lamp source type, lumens output and wattage

c. Mounting height with distance noted to the nearest property line for each luminaries

d. Types of timing devices used to control the hours set for illumination, as well as the proposed hours when each fixture will be operated

e. Total Lumens for each fixture and total square footage of areas to be illuminated 
f. For all plans of more than three fixtures: A Calculation Summary indicating foot-candle levels on the lighting plan, noting the maximum, average and minimum, as well as the uniformity ratio of maximum to minimum and average to minimum levels (TILE, 2015)

6. Foot-Candle distribution, plotting the light levels in foot-candles on the ground and the designated mounting heights for the proposed fixtures. Maximum luminance levels should be expressed in foot-candle measurements on a grid of the site showing foot-candle readings in every five or tenfoot square. The grid shall include light contributions from all sources (GGELP, 2009)

Security lighting increases visibility around perimeters, buildings, storage tanks and storage areas, loading docks, as well as in buildings, hallways and parking lots. It is a security management tool that is applicable in almost all environments within a transit system and should be considered when agencies are installing and updating other access management subsystems, particularly those focusing on surveillance. Security lighting allows the security force to visually monitor the lighted areas, making it difficult for someone to enter the facility undetected and facilitating the apprehension of offenders. Determining which system is appropriate for a given application depends on the identified risk control requirements of the facility

At a minimum, all access points, the perimeter, restricted areas and designated parking areas should be illuminated from sunset to sunrise or during periods of low visibility. In some circumstances, lighting may not be required, but these circumstances must be addressed in the facility security plan. The plan must show that the absence of lighting will not adversely impact risk and should include the alternative measures being used. Agencies should understand that undesirable shadowing will exist and the total elimination of shadowing is not practical in all areas. However, lighting need also be appropriate to the operating environment. Agencies should consider the environment where stations and other infrastructure are located, so as to make lighting appropriate to the area. More residential environments may be less receptive to bright, consistent lighting. Agencies should consider methods of making lighting safe, attractive and neighborhood-friendly, such as high-level, indirect lighting, multiple low-level lights, or some combination of both.

Glare is a state in the visibility process connected with a feeling of discomfort and/ or a reduction in the ability to do visual tasks due to too high a luminance in the field of view or an improper luminance distribution in time and space (Słominski, 2016). In (Chen et al., 2016) the authors described two experiments that were designed to investigate the museum lighting environment in terms of correlated colour temperature and illuminance.
In this study; each of: Security lighting design, illumination requirements, calculations and, Determination of cameras' parameters of the surveillance system, at the external perimeter area of hypothetical research reactor facility (HRRF), will be provided. A perimeter area has an isolation zone between double fences which surrounds the HRRF-site. The number of illumination poles (electricity towers) and lamps types are needed for camera surveillance system will be computed and determined. Also a distribution of television cameras and parameter's calculation will be provided.

\section{Hypothetical Reactor Facility (HRRF)}

Hypothetical nuclear site is a simulation site for implementation the design process of the Physical Protection System (PPS). HRRF is located in a hypothetical country and contains the following buildings: Main Entrance (ME), Reactor Research Building (R.R), Isotope Production Facility (IPF) and Nuclear Fuel Manufacturer Plant (NFMP) (LANL, 2013).

The nuclear complex surrounded by an external double peripheral fence which considers the first perimeter fence and it contains an isolation zone. HRRF site have one main entrance access. It consists of two gates: Personal portal gate and vehicle gate which are located in the middle of the left side of the fences. After you passing the gates, you are in the protected area. Figure (1) shows the Hypothetical Research Reactor Facility. Peripheral Fence is the first barrier for unauthorized access of people to the nuclear facility. It forces its personnel to enter or exit at one point, the main guard, where personnel involved in security activities will be found. Peripheral fence has been designed to protect HRRF-site is $2.5 \mathrm{~m}$ chain link double mesh fence with an isolation zone. Fences cover the total peripheral near to $1180 \mathrm{~m}$ long $(350 \mathrm{~m} \times 240 \mathrm{~m})$ length, surrounding the whole site and with a separation of $10 \mathrm{~m}$ wide of isolation zone between two fences, (Except for main guard location), Designs consider that the fence plane-side overview shape is rectangular and no detection sensors installed on the outer and inner fences (SAR, 1999).

A Closed Circuit Television system (CCTV); is essential to identify the cause of an alarm (intrusion process) and to determine if an alarm is true or false. Many of fixed and moving cameras should be installed at the isolation zone. Camera surveillance system needs sufficient illumination according to camera technical specifications. Using of Infrared and cameras with high technical specifications needs more costs. If the designer calculate appropriate illuminations and select the optimal lamps type taking into accounts the factors to consider in selecting a lighting type, suitable for cameras requirements such as lux over object, it will reduce the costs. 


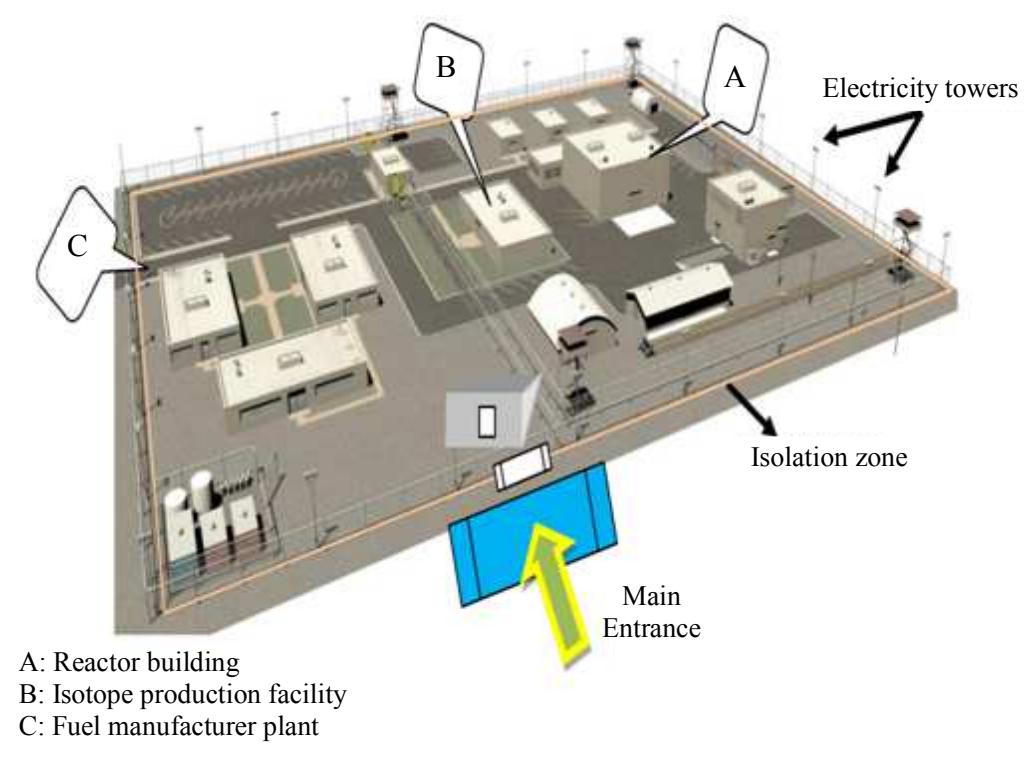

Fig. 1: Hypothetical reactor facility (LANL, 2013)

\section{Peripheral Security Lighting Design}

The lighting requirements vary according to each security application (object illumination, physical deterrence and psychological deterrence). All of these applications have different requirements for intensity, distribution, quality, sources and reliability. In addition lighting design must consider the following items:

- Where perimeter lighting is required, the lighting units for a perimeter fence should be located a sufficient distance within the protected area and above the fence so that the light pattern on the ground will include an area both inside and outside the fence

- Perimeter lighting should be continuous and on both sides of the perimeter fence and should be sufficient to support CCTV and other surveillance equipment where required

- The cone of illumination from lighting units should be directed downward and outward from the structure or area being protected. Cones of illumination should overlap to provide coverage in the event of bulb burnout

- The lighting should be arranged so as to create minimal shadows and minimal glare in the eyes of security guards

\section{Lamps Type Selection}

There are many different types of lamps used in modern protective lighting systems:

- Incandescent

- Fluorescent
- Mercury vapor

- Metal halide

- High Pressure Sodium (HPS)

- Low Pressure Sodium (LPS)

Each has its own unique characteristics which determine when the particular lighting is suited to a particular task. For example, LPS provides relatively high levels of illumination at low cost. Often they are used to light highways; however, LPS lamps tend to distort colors significantly. Mercury vapor, metal halide and HPS are known as High-Intensity Discharge (HID) lamps. These lamps provide the highest efficiency and longest service life of any lighting type. They are commonly used to outdoor lighting and in large indoor areas. Some factors must be considered in selecting lamp type such as:

- The lumens per watt

- Color rendering

- Focusing capability

- Warm-up time

- Restrike time

- Lamp life (IEC 60598.2.3, 2002)

Illumination quality is the combination of these entire individual factors. As in all security applications, determining the specific use for lighting will define the illumination quality of the lighting system. Luminaries of the enclosed type utilizing HPS lamps will be used. Selection of the light source will be made from High Intensity Discharge (HID) sources because of their luminous efficacy. The advantages and disadvantages of various lighting sources are listed in Table 2: 
- HPS lighting is the most energy efficient source which has an acceptable color rendition

- Metal halide lamps have a good color rendition, but luminous efficacy, lumen maintenance (lumen output diminishes more rapidly throughout life), length of life and restrike time make them a less than desirable source for many applications

- Incandescent lighting not desired because of the extremely low luminous efficacy and short lamp life

- Mercury vapor lighting is also not desired because of lower luminous efficiencies, poor lumen maintenance, higher life cycle costs and environmental considerations (mercury propagation and disposal)

- Unacceptable sources. Fluorescent lighting has not been included in Table (2) due to its relatively low luminous efficacy and the limited control possible with the tubular shape. Low pressure sodium lighting is also not included, as the color is monochromatic and therefore is not considered suitable for general use. The amount of sodium in low-pressure sodium lamps requires special disposal methods (IEC 60662, 2011)

\section{Illumination Poles Locations}

For a given scene to be visible to a camera the scene should be illuminated by light and a certain amount of this light must be reflected into the camera lens. For the CCTV system, the most important parameters in lighting system are its minimum intensity and its evenness of illumination. So, the function of the external lighting system is to illuminate the alarm location evenly with enough intensity for the chosen camera and lens system. The exterior lighting system is designed to have an average value of light level greater than 10 lux. The evenness of illumination is characterized by the light-to-dark ratio, which is the ratio of maximum to minimum intensity. The system is designed to get a ratio of 6:1. The Exterior Lighting System consists of illumination poles covering the entire length of the peripheral fence, in the clear zone, an Uninterruptable Power Supply (UPS) system with sufficient capacity to provide year-round $24 \mathrm{~h}$ operation and all related connections and accessories. A number of poles will be determined to locate around the site. They are $8 \mathrm{~m}$ height and installed $2 \mathrm{~m}$ away from the interior fence. It is necessary to calculate the suitable distance between poles (poles span) where the distance between the two fence edges equal ten meters and the distance between the pole and the two fence edges equal 2 and $8 \mathrm{~m}$ respectively. Figure (2) shows the double fences luminaries location and Dimensions.

Sufficient illumination must be available to accomplish the observation. For CCTV, the camera specifications required the minimum illumination (Emin) $=0.16$ as a percent of the maximum illumination where:

$\left(\mathrm{Emin} / E_{\max }=1: 6, E_{\min } / E_{a v}=1: 3\right)$

So: $E_{\min } / E_{\max }=0.16$

When, $H$ is the pole height $=8 \mathrm{~m}$ and install with a distances equal to 2 and $8 \mathrm{~m}$ from the two edges of the fences.Calculation of the distance between the line of the poles and the two edges of the fences as a function of (H) will be.

The line (A-A) with a distance $(2 / 8) * H$ and the line (B-B) with a distance of $(8 / 8) * H$ as shown in the isolux diagram in Fig. (3).

Suppose we have 2 poles and the ratio $E_{\min } / E_{\max }=$ 0.16 So:

$$
\begin{aligned}
& E_{\min }(\text { pole } 1)+E_{\min }(\text { pole } 2)=16 \% \\
& E_{\max } \text { and for each pole } E_{\min }=8 \% E_{\max }
\end{aligned}
$$

- So, the points $a, b$ will be recorded at $8 \%$ curve on the isolux diagram.

- $\quad$ From the curve the distance between 2 poles (poles span) " $S$ "will be calculated as:

$$
\begin{aligned}
& \mathrm{S} / 2=2(1.05 \mathrm{H}) \text { meter } \\
& \mathrm{S}=4(1.05 \mathrm{H})=4 * 1.05 * 8=34 \mathrm{~m} \text { and }
\end{aligned}
$$

Total number of poles $=$ the length of the

fence / poles span

No of poles $=1180 \mathrm{~m} / 34 \mathrm{~m}=35$ poles

\section{Luminaries Characteristics}

Luminaries comprise a hexagonal structure of cast aluminum with a demountable connection box and a frame supports the reflector glass. It has two anodized aluminum demountable mirrors for better light reflection and performance. It contains a high pressure sodium vapor lamp that has power consumption of 250 Watts and luminous flux of $28000 \mathrm{~lm}$. Of course, like any other electrical equipment, the luminary complies with safety requirements regarding electrical Insulation and Protection (IP65):

$$
E_{a v}=(U . F * M . F * \text { Lumen }) /(D * W)
$$

Where:

$E_{a \mathrm{v}} \quad:$ (Average Lighting Level)

$D \quad$ : Distance between two poles in meter

$W \quad$ : Area width in meter

Lumen : Flux per lamp (26000 from the selected lamp characteristics)

U.F : Utilization factor ( $=0.35$ from utilization curve)

M.F : Maintenance factor (= 0.8 from selected lamp characteristics) 
Amie Abdel Wadoud and Alaa Abdelwahab Saleh / American Journal of Applied Sciences 2018, 15 (1): 84.94 DOI: 10.3844/ajassp.2018.84.94

Table 2: Comparison of lamps types properties (IEC 60598.2.3, 2002)

\begin{tabular}{llll}
\hline Property & HPS & Metal halide & Mercury vapor \\
\hline Watt & $35-1000$ & $50-2000$ & $40-1250$ \\
LM/Watt & $80-140$ & $80-100$ & $45-63$ \\
Warm up time & 2-5 Minute & $5-8$ Minute & T-8 Minute \\
Restrike time & 1 Minute & $10-20$ Minute & $10-20$ Minute \\
Color rendition & Fair to good & Excellent & Fair to good \\
Focusing & Good to excellent & Good & Good \\
Cost & High & High & High \\
Lamp life & $2.5-6$ & $1.3-5$ & $3-6$ \\
\hline
\end{tabular}

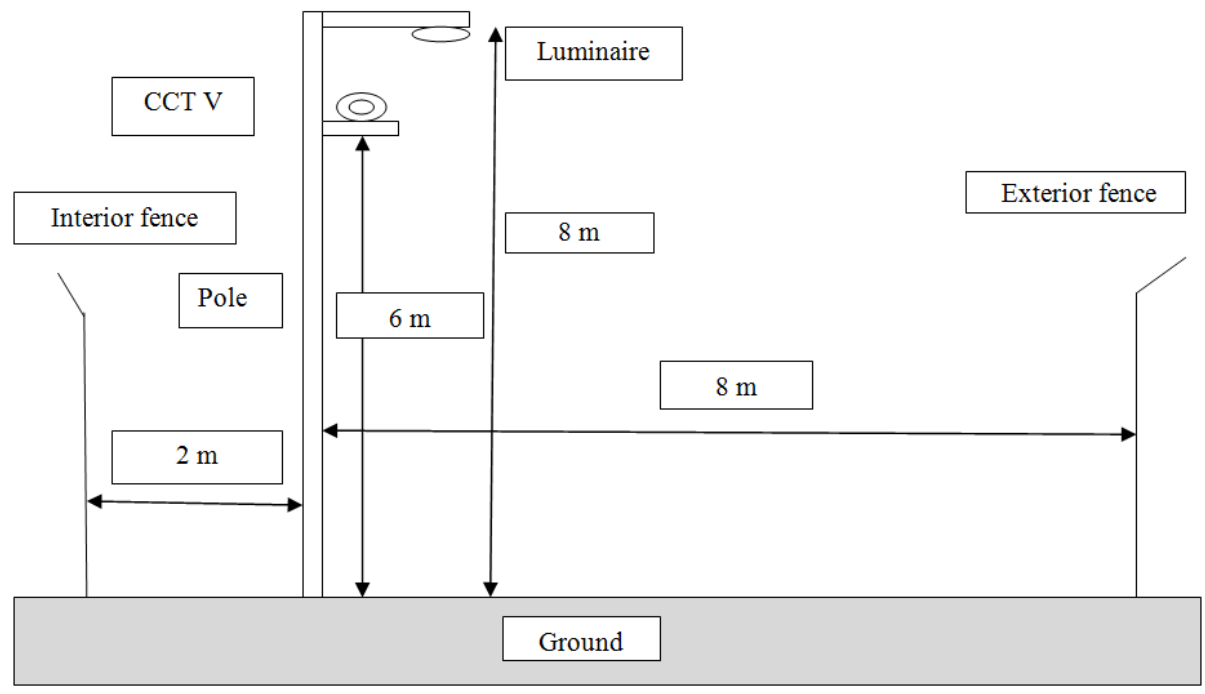

Fig. 2: Double fences luminaries location and dimensions

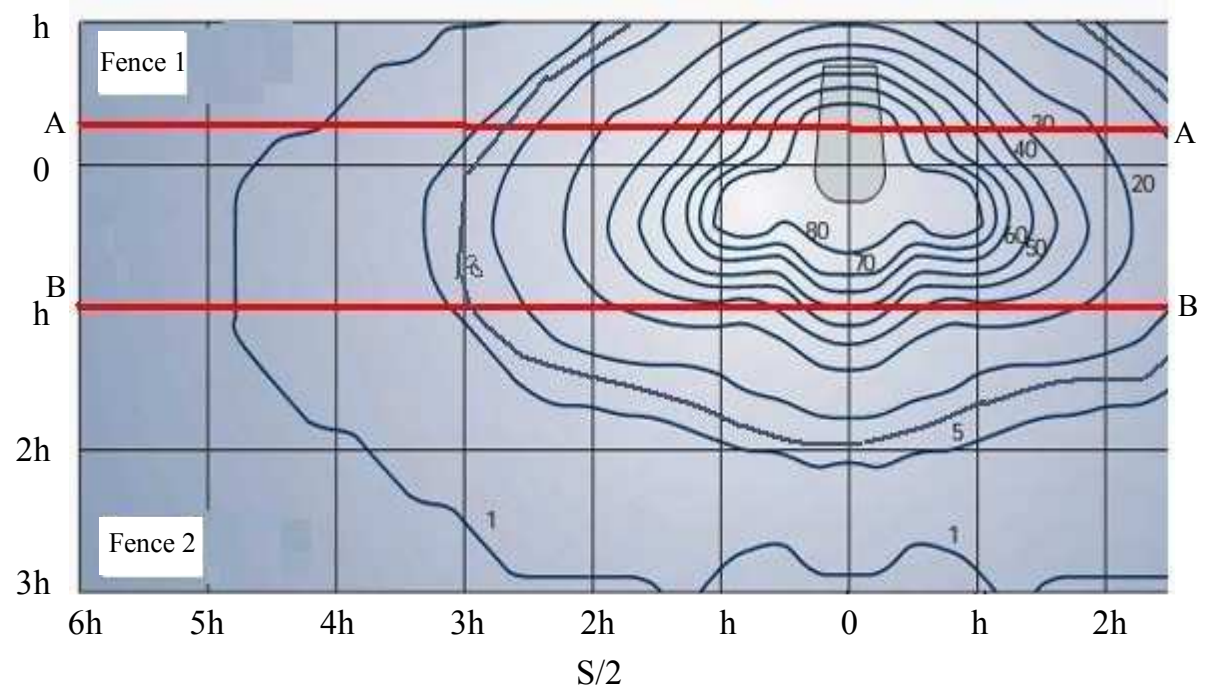

Fig. 3: Isolux diagram

From the previous equation the $E_{a v}$ can be calculated as follows:

$E_{a v}=(0.35 * 0.8 * 26000) /(34 * 10)=21 \mathrm{Lux}$

Average Lighting Level $\left(E_{a v}\right)=21$ Lux
$E_{\text {min }}=21 / 3=7$ Lux

Minimum Lighting Level $\left(E_{\min }\right)=7$ Lux

Table (3) listed the illumination calculations and final results. 
Table 3: Lighting calculations and results

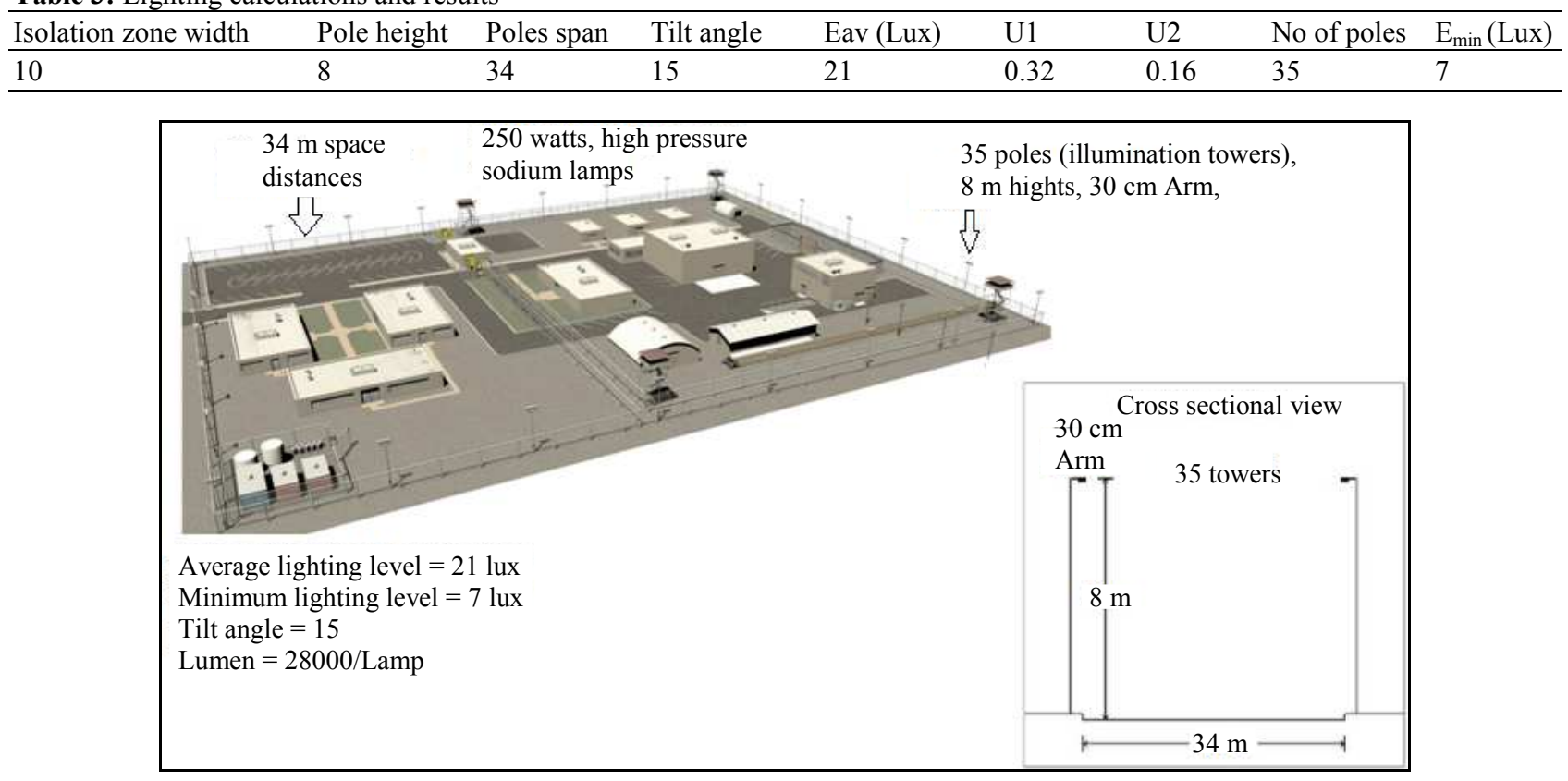

Fig. 4: HRRF illumination distribution and poles types

Where:

U1 : (Min./Average Lighting Level) $\geq 32 \%$

U2 : (Min./Max. Lighting Level) $\geq 16 \%$

$E_{\min } \quad:$ Lux (Minimum Lighting Level)

Diffuser : Polycarbonate

Lamp : 250w, High Pressure Sodium

Pole Arm : $30 \mathrm{~cm}$

From the previous calculations, the Illumination distribution and poles types at HRRF-site will be arranged as shown in Fig. (4).

\section{Surveillance System Parameters}

A CCTV system is essential to identify the cause of an alarm and to determine if an alarm is true or false. The purposes of camera surveillance system are to determine the cause of a sensor alarm and to provide information about an intrusion (SNL, 2004). According to determination of cameras requirements and illumination calculations as mentioned above, black and white or low lux colored fixed and moving cameras can be used and mounted in isolation zone. This means that there are low cost will be pushed. External moving cameras, located at the plan view corner of the perimeter. The Exterior CCTV System consists of fixed cameras for a general inspection and Pan-Tilt and Zoom (PTZ) cameras for a detailed observation.

\section{Cameras Type Determination}

Monochrome Cameras (Black and white), 420 lines resolution and Cameras of 1/4-Inch format from VICON type or equivalent will be used. They have a highsensitivity Charge-Coupled-Device (CCD) image sensor and solid-state circuitry that provide long life and high reliability. All cameras have auto iris lenses, low light capability, output level control and self identification generator. An incorporated automatic linear electronic shutter responds automatically to changes in light level by increasing or decreasing the integration period of the chip. The linear shutter range is $1 / 50-1 / 10000$ second. Lens size is chosen according to supervision area of each one of the cameras (VICON, 2012).

\section{Camera Parameter Calculations}

Many cameras' parameters, which consider important factors in designing CCTV system, should be computed and/ or determined, these parameters, are:

- Lens Format

- Lens focal length calculation

- F-Number

- Width of images sensitive area

- Angle of view calculation (Wadoud, 2013)

\section{Cameras Lens Format}

The length format size defines the maximum usable image created by the lens, 1/4-Inch format, (3.6 Constant Width, 2.7 Constant Heights), will be used, for the exterior cameras between the double fences, $10 \mathrm{~m}$ width isolation zone, which are illuminated by 34 Poles, 250 awatts high pressure sodium lamps (26000 lumen/pole) and 7 lux minimum light level, these format are suitable, cheapest and low maintenance (TOAEI, 2005). 


\section{Lens Focal Length and Subject Dimensions Calculation}

Focal length is the single most important factor in proper lens selection. It determines the relative magnification of the object. Since the format of a lens is known, the focal length will define the angular fields of view (horizontal and vertical angles covered by lens), thus defining the width and height to the field of view for the camera for any object distance (Stanislav, 2006).

According to the external perimeter fence dimensions, the required wide image area (W) is $10 \mathrm{~m}$ (distance between the two double fences), HRRF-Site fences covers the total peripheral near to $1180 \mathrm{~m}$ long $(350 \times 240 \mathrm{~m})$ rectangular shape, 10 protected (supervision) zones, surrounding the whole site and with a separation of $10 \mathrm{~m}$ space of isolation zone between two fences, (Except for main guard location) and sides zone configuration as follows:

- Two Long sides: Are $350 \mathrm{~m}$; each side has 3 supervision zones (116.6 m/zone)

- So that; (L) is the Distance between subject and camera $=116.6 \mathrm{~m}=\sim 120 \mathrm{~m}$

- Two short sides: Are $240 \mathrm{~m}$; each side has 2 supervision zones (120 m/zone),

- So that; (L) is the Distance between subject and camera $=120 \mathrm{~m}$

- Lens focal length (mm) of the cameras can be obtained from the formulas:

For $1 / 4$ " inch camera format type, the equation is:

$$
W=3.6 / F \times L(m) ; H=2.7 F \times L(m)
$$

Where:

$W:$ Width of subject

$H:$ Height of subject

$L$ : Distance between subject and camera (Fig. 5)

$F$ : Lens focal length (mm) (Cieszynski, 2004)

So the Lens focal length can be obtained from Equation (1) as follows:

$$
10(m)=3.6 / f \times 120(m) \quad f=43.2
$$

According to the manufactured focal lens types founded we choose the nearest values:

$$
\text { Lens focal length }=50 \mathrm{~mm}
$$

Height $(\mathrm{H})$ of the subject can be computed by:

$$
\begin{aligned}
& H=2.7 / F \times L(m)] \\
& H=(2.7 / 50) \times 120 \\
& H=6.4 \mathrm{~m}
\end{aligned}
$$

The image area Dimensions $(W \times H)$ is $=10$ width $\times 6.4$ height as illustrated in Fig (5).

\section{F-Stop Number Calculation}

F-Number is an important lens parameter is its aperture setting called an f-stop, which is the lens' measure of its ability to gather light. The smaller the f-stop, the light is admitted; therefore, a small f-stop (1.2 to 1.8) is desirable for exterior assessment applications. F-stop is ratio between lens focal length $(50 \mathrm{~mm})$ and aperture opening.

If aperture opening is 27.7 the f-stop number will be:

$$
F-\text { stop number }=1.8
$$

\section{Width of Images Sensitive Area Calculation}

The width of image sensitive area can be calculated from the equation:

$$
D=W(f / w)
$$

Where:

$D$ : Distance from the camera (m)

$W:$ is width of field of view (m)

$f \quad:$ is focal length of lens ( $\mathrm{mm})$

$w:$ is width of images sensitive area $(\mathrm{mm})$

Computation of the width of images sensitive area by substitute on Equation (2):

$$
120=10(50 / w)
$$

Width of Images Sensitive Area $(w)=4.1$

\section{Angle of View Calculation}

The angular range covered by a camera is referred to as its "angle of view" and is determined by the focal length of the lens and the size of the imager (CCD) on which the picture is formed. The angle of view is expressed by the following formula:

$\theta=2 \tan ^{-1}\left(\frac{1 / 2}{f}\right)$

Where:

$\theta$ : Angle of view

I: Effective dimension of $\mathrm{CCD}(\mathrm{mm})$

$f$ : Lens focal length (ITS, 2000)

By substituting in Equation (3) by lens focal length 50 $\mathrm{mm}$ and effective dimension of CCD $4.6 \mathrm{~mm}$ (selected technical specification of model VC2130-24 from VICON) the angle of view will be: Angle of view $(\theta)=5.26$ degree.

The calculation results are illustrates in Table (4).

\section{Determination of Cameras Numbers and Locations}

From the previous calculations, a total of ten fixed cameras are placed and distributed as shown in Fig. (6), on the isolation zones of the double fences and installed on $6 \mathrm{~m}$ iron steel columns and their view is in the opposite direction to make interference on image viewer area and they will protect themselves (MHB, 1987). 


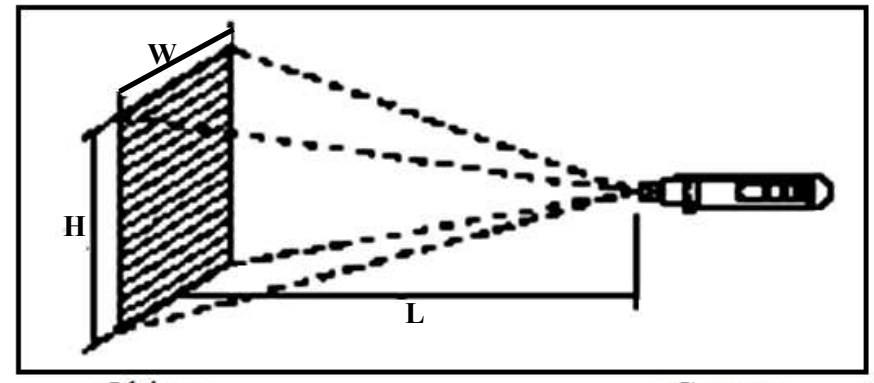

Object

Camera

Fig. 5: View field

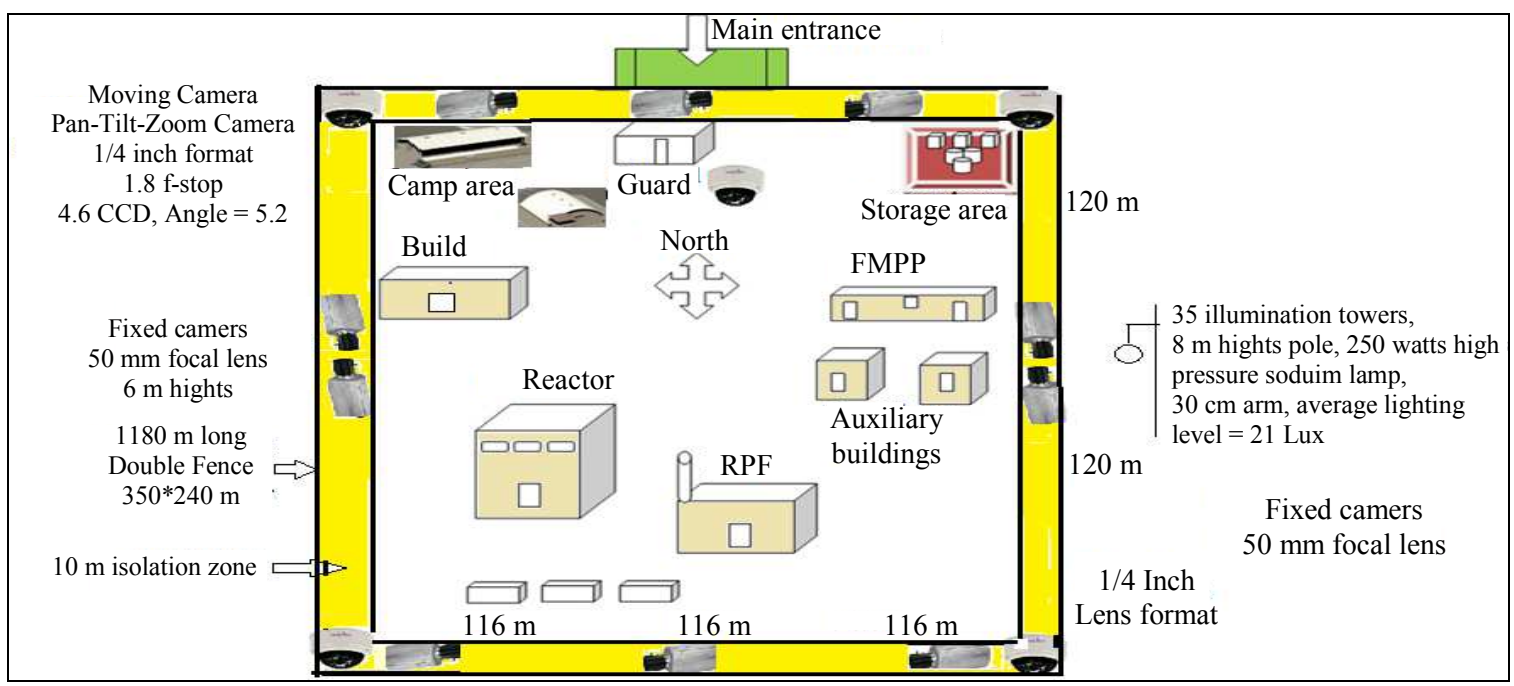

Fig. 6: Peripheral fence camera's distributions

Table 4: External camera parameters results

\begin{tabular}{|c|c|c|c|c|c|c|c|}
\hline Item area & Lens format & Lens focal length & F-stop number & Height & $\begin{array}{l}\text { Images sensitive } \\
\text { area (w) }\end{array}$ & $\begin{array}{l}\text { Angle of } \\
\text { view }(\theta)\end{array}$ & $\begin{array}{l}\text { Number of } \\
\text { cameras }\end{array}$ \\
\hline Isolation zone & 1/4" Inch & $50 \mathrm{~mm}$ & 1.8 & $6.4 \mathrm{~m}$ & 4.1 & $5.262^{\circ}$ & 15 \\
\hline
\end{tabular}

The fixed cameras should be distributed as follows:

- Four (4) Fixed Cameras/two short sides

- Six (6) Fixed Cameras/two long sides and

The fixed cameras should be aided by four moving cameras (Pan-Tilt Zoom)/perimeter fence corners and one moving cameras (Pan-Tilt Zoom) located on the top of Guard building. Cameras image sensitive area $(\mathrm{W} \times \mathrm{H})$ is $=10 \mathrm{~m}$ width $\times 6.4 \mathrm{~m}$ height. Cameras columns height $(6 \mathrm{~m})$ is lower than the illumination towers height $(8 \mathrm{~m})$, which stand at the isolation zone, $2 \mathrm{~m}$ far from the internal fence. Moving Cameras are used for identification and recognitions. Pan-tilt and zoom units will have $350^{\circ}$ panoramic movements and full $\pm 90^{\circ}$ updown movement capacities, all cameras are linked to a central CCTV programmable digital matrix, 16 cameras inputs/6 output monitors (Garcia, 2001). Isolation zone or cameras supervising area will be illuminated by 35 electric towers, (30 cm Arm, 15 Degree Tilt Angle) with, (250 Watts) high-pressure sodium lamps (26000 Lumen/Lamp), to produce 7lux minimum light level.

\section{Results and Discussion}

For perimeter lighting, where the objective is to create an illuminated strip, usually around $10 \mathrm{~m}$ wide, also designed to have a sharp cut-off so as not to illuminate the domestic properties outside which they are located, this feature meets the need not to illuminate guards who may be patrolling inside the illuminated perimeter. Ideally the lighting columns and their lanterns should be so located that the ground immediately outside 
the fence is adequately illuminated but the inside face of the fence is not, allowing guards clear vision through the fence fabric. The lighting columns should be positioned at least $2.0 \mathrm{~m}$ inside the fence line so they will not aid an intruder to scale any physical barrier or defeat any perimeter intruder detection system. The maximum height of columns should be specified. A recommended maximum height would be 8.0 metres. Covers giving access to fused cut-outs should require a tool to open or be fitted with a lock. Where a specific threat is identified intrusion detection may be fitted. The value of illumination specified will depend on the particular lighting scenario which is to be used and the CCTV system requirement. The variation in horizontal illumination level, (uniformity), within the area to be lit should not exceed 3 to 1 (average to minimum) when all lamps are lit. A minimum horizontal illumination level of 5 Lux operational (7 Lux on commissioning) should be the design criteria. An allowance may be added to allow for deterioration of lamp output as the lamp ages and dirt builds up on the luminaire together with possible reductions in supply voltage. A rough guide is to assume luminaires will be spaced at 3 to 4 times their mounting height. High pressure Sodium 250 watt lamps will be used for security lighting which have a high efficacy-around $80 / 100 \mathrm{~lm} / \mathrm{W}$, a life in excess of $8000 \mathrm{~h}$ and reasonable colour rendering. Igniter circuits ensure starting at low temperatures and a restrike within one minute in the event of a supply interruption extinguishing the lamp.

We made Uniformity measuring to test the design. In the uniformity measuring we should measure selected point(s) around the perimeter. It should be noted that the following assumes that the lighting between any two adjacent columns will be symmetrical about the centre line drawn at a midpoint between the columns. This means that we only need to consider the uniformity of the illuminated strip between a column centre line and the mid-point centre line. To calculate the horizontal uniformity of the lighting we divide the illuminated strip up into a number of squares. We then measure the illumination at the centre of each square, taking the average of the values recorded. The minimum value for the strip is taken as the minimum of the values recorded. The uniformity is then the ratio of the average value to the minimum value recorded. The size of the squares taken will determine the accuracy of the value obtained. In our design the columns are taken to be $34 \mathrm{~m}$ span, illuminating a $10 \mathrm{~m}$ wide area. A realistic measurement grid would be to use $2 \mathrm{~m}$ squares giving a total of 40 readings. To achieve repeatability the area should be marked out in a grid. The grid marks the measurement positions of the notional squares. Measurements would be taken at the grid intersections. After measuring the uniformity it was 3to1 and it is the optimum desired value in related to standard, guidance and advice. According to determination of cameras requirements and illumination calculations as mentioned above, black and white or low lux colored fixed and moving cameras can be used and mounted in isolation zone. From the previous calculations, a total of 10 fixed and 5 moving cameras are placed and distributed on the isolation zones of the double fences and installed on $6 \mathrm{~m}$ iron steel columns and their view is in the opposite direction to make interference on image viewer area and they will protect themselves. Also cameras' parameters, which consider important factors in designing CCTV system have been computed and determined, these parameters are $50 \mathrm{~mm}$ focal lens, $1 / 4$ inch format, , $1.8 \mathrm{f}$-stop number, image sensitive area with 5.2 angle of view.

\section{Conclusion}

Security lighting is an important part of the perimeter security plan on most projects, a little consideration is given to the security design and layout. Usually, lights are installed without security plan consideration. Then the images from the Closed Circuit Television system (CCTV) along the perimeter of the property are not very good and usually are of poor quality. In this study a proposed design for illumination and cameras surveillance system for optimum supervision at a perimeter area of nuclear facility are presented. A perimeter area has an isolation zone between double fences which are surrounds the nuclear facility site. The illumination poles, lamps type, towers span distance and lighting level, required for camera surveillance system are computed and determined. The work provided the requirements of cameras surveillance system at nuclear reactors isolation zone. A calculation of camera's parameters and its technical specifications is presented for a nuclear research reactor facility. A distribution of the cameras locations inside the isolation zone of the nuclear site is explained and designed depending on the calculated camera's parameters and specifications. The results shows that the nuclear facility site isolation zone needs fifteen cameras, (10 fixed and 5 moving), with $50 \mathrm{~mm}$ focal lens, $1 / 4$ inch format, with 5.2 angle of view. Cameras supervising area should illuminated by 35 electric towers, (30 cm Arm, 15 Degree Tilt Angle) with, (250 Watts) high-pressure sodium lamps (26000 Lumen/Lamp), to produce 7lux minimum light level for optimum supervision.

\section{Acknowledgement}

$\begin{array}{ll}\text { HPS } & : \text { High Pressure Sodium } \\ \text { LPS } & : \text { Low Pressure Sodium } \\ \text { HID } & : \text { High-Intensity Discharge } \\ \text { CCTV } & \text { Closed Circuit Television system } \\ \text { UPS } & : \text { Uninterruptable Power Supply ) } \\ \text { Emin } & : \text { Minimum illumination } \\ \text { Emax } & : \text { Maximum illumination } \\ \mathrm{S} & : \text { Poles span } \\ E_{a \mathrm{v}} & : \text { (Average Lighting Level) }\end{array}$


$D \quad$ : Distance between two poles in meter

$W \quad$ : Area width in meter

Lumen : Flux per lamp (26000 from the selected lamp characteristics)

U.F : Utilization factor ( $=0.35$ from utilization curve)

$M . F$ : Maintenance factor (= 0.8 from selected lamp characteristics)

$F:$ Lens focal length ( $\mathrm{mm})$

$D$ : Distance from the camera (m)

$W:$ Is width of field of view (m)

$f \quad:$ Is focal length of lens $(\mathrm{mm})$

$w$ : Is width of images sensitive area (mm)

\section{Author's Contributions}

Amir Abdel Wadoud: Contribute in drafting the article or reviewing it critically for significant intellectual content.

Alaa Abdelwahab Saleh: Conception, design, Analysis data, give final approval of the version to be submitted and any revised version.

\section{Ethics}

This article is original and contains unpublished material. The corresponding author confirms that all of the other authors have read and approved the manuscript and there are no ethical issues involved.

\section{References}

Michael, J. and J. Arata, 2006. Perimeter Security. 1st Edn., McGraw-Hill, New York.

Kukula, F.P. and S.J. Elliott, 2004. The effects of varying illumination levels on FRS algorithm performance. Purdue University.

Vermeulen, J., 1992. Light sources and closed-circuit television. Light. Res. Technol., 24: 63-67.

TILE, 2015. Security lighting, guidance for security managers. Institution Light. Engineers.
GGELP, 2009. Guidelines for good exterior lighting plans. Dark Sky Society.

Słominski, S., 2016. Identifying problems with luminaire luminance measurements for discomfort glare analysis. Lighting Res. Technol., 48: 573-588.

Chen, H.S., C.J. Chou, H.W. Luo and M.R. Luo, 2016. Museum lighting environment: Designing a perception zone map and emotional response models. Lighting Res. Technol., 48: 589-607.

LANL, 2013. Hypothetical Facility Data Book: The Shapash Nuclear Research Institute (SNRI). 1st Edn., Los Alamos National Laboratory.

SAR, 1999. Egyptian Second Research Reactor (ETRR-2) security system basic design'. Safety Anal. Report.

IEC 60598.2.3, 2002. Luminaries for road and street.

IEC 60662, 2011. High Pressure Sodium vapor lamps.

SNL, 2004. Physical protection of nuclear facilities and materials. Proceedings of the 18th International Training Course, Sandia National Laboratories, Albuquerque, New-Mexico, USA.

VICON, 2012. Fixed camera, data/specification sheet/part number: 8009-7259-00-00. VICON Industries Inc.

Wadoud, A.A., 2013. Determination of television surveillance cameras' parameters of hypothetical nuclear facility. Arab J. Nuclear Sci. Applic., 48: 129-142.

TOAEI, 2005. Closed circuit television systems fundamentals course. TOA Electronics, Inc., USA.

Stanislav, U., 2006. The principles of CCTV Design in Video-CAD. CCTV-Cad.Com.

Cieszynski, J., 2004. Closed Circuit Television. 2nd Edn., Elsevier.

ITS, 2000. Closed-circuit television (CC.TV) cameras design manual. Intelligent Transportation Systems.

MHB, 1987. Design Guidelines for Physical Security of Facilities. 1st Edn., Military Handbook, USA.

Garcia, M.L., 2001. The Design and Evaluation of Physical Protection System. 1st Edn., ButterworthHeinemann, Boston, ISBN-10: 0750673672, pp: 313. 